\title{
Parental Involvement Among Collegiate Student-Athletes: An Analysis Across NCAA Divisions
}

\author{
Katie Lowe \\ Clark University \\ Miranda P. Kaye \\ Pennsylvania State University \\ Logan Lyons \\ Utah State University
}

\author{
Travis E. Dorsch \\ Utah State University \\ Jeffrey Jensen Arnett \\ Clark University \\ Amanda N. Faherty \\ Clark University
}

\section{Lindsey Menendez Utah State University}

\begin{abstract}
Despite emerging evidence of a link between parental involvement and studentathletes' (SA) experiences, and the desire for educational programming for parents of these SAs, previous research has been limited to the Division I level. This has prevented the ability to inform, develop, and deliver parent programming across the NCAA's diverse membership. The present study was designed to descriptively assess SA reports of parental involvement (i.e., support, contact, academic engagement, athletic engagement) across NCAA Division I, II, and III member institutions and examine the potential impact of this involvement on SAs' experiences (i.e., academic self-efficacy, athletic satisfaction, well-being, individuation). Participants were 455 SAs $\left(53 \%\right.$ female; $81 \%$ Caucasian; $M_{\mathrm{age}}=$ $19.81, S D=1.65)$ from DI (30\%), DII (37\%), and DIII (33\%) institutions, who completed an online survey with items assessing parental involvement and SA experiences. Regarding academic classification, 32\% were freshmen, 24\% sophomores, $22 \%$ juniors, and $22 \%$ seniors. Results provide novel evidence for an absence of division-wide differences in average levels of involvement and no variability in links between involvement and SA experiences across divisions. Results complement and extend previous research by offering a clearer
\end{abstract}

\footnotetext{
Lowe, Arnett, and Faherty are with the Dept. of Psychology, Clark University, Worcester, MA. Dorsch, Lyons, and Menendez are with the Dept. of Family, Consumer, and Human Development, Utah State University, Logan, UT. Kaye is with the Clearinghouse for Military Family Readiness, Pennsylvania State University, University Park, PA. Address author correspondence to Katie Lowe at katielowe85@ gmail.com.
} 
understanding of differential associations between involvement and SAs' experiences regardless of division, notably that involvement bolstered well-being but also strongly detracted from individuation. Findings highlight the importance of developing programs to promote positive and developmentally-appropriate parental involvement across the spectrum of intercollegiate athletics, especially given the absence of evidence-based resources presently offered by the NCAA.

Keywords: development, emerging adulthood, intercollegiate athletics, parenting, well-being

Interest in parental involvement in youth sport has surged in response to the privatization and institutionalization of youth sport in America and the emphasis on early sport specialization (e.g., Dunn, Dorsch, King, \& Rothlisberger, 2016; Gregory, 2017; Malina, 2010). This robust scholarship has yielded theoretical lenses for understanding the parental role in youth sport (e.g., Fredricks \& Eccles, 2005), documented differential effects of involvement on sport outcomes during childhood and early adolescence (e.g., O’Rourke, Smith, Smoll, \& Cumming, 2014; Stein, Raedeke, \& Glenn, 1999), and inspired interventions to promote positive parental involvement in youth sport (e.g., Dorsch, King, Dunn, Osai, \& Tulane, 2017; National Youth Sports Health \& Safety Institute, 2013). However, the breadth and richness of this youth sport literature and its application is not matched at the intercollegiate level. Indeed, it was not until 2015 that the National Collegiate Athletic Association (NCAA) added items on parental involvement to their Growth, Opportunities, Aspirations and Learning of Students in college $(G O A L S)$ survey; shortly after that, seminal work linking involvement to studentathlete (SA) development was published in the academic literature (Dorsch, Lowe, Dotterer, \& Lyons, 2016a; Dorsch, Lowe, Dotterer, Lyons, \& Barker, 2016b). As such, parental involvement in intercollegiate sport and its links to SAs' academic, athletic, and developmental outcomes is a recent area of study that includes a small collection of nonperiodical descriptive reports and peer-reviewed literature, respectively.

Because parents remain key sources of support during the transition to intercollegiate athletics (e.g., Côté, 1999; Wylleman \& Lavallee, 2004), a time period that aligns with the developmental life stage of emerging adulthood (Arnett, 2015), more systematic research is warranted to enhance understanding of parental involvement in intercollegiate athletics. Further, since SAs are at risk for academic problems, depressive symptoms, and risky behaviors (see NCAA, 2016; Wechsler, Davenport, Dowdall, Grossman, \& Zanakos, 1997; Wolanin, Gross, \& Hong, 2015), it is important to understand how parents may either facilitate or thwart SAs' development during this life stage. The intersection of three key factors also underscore timely attention to parental involvement in college sport: (a) increased popular media reports on types of parents (e.g., "the Sideline Coach") whom college coaches report avoiding during recruitment because they produce the least coachable and resilient SAs (e.g., Bastie, 2017); (b) recent work highlighting NCAA coaches' and administrators' perceptions of negative parental involvement, and their unanimous desire to develop programs to leverage more positive involvement (Dorsch et al., 2016b); and (c) the absence of parenting resources presently offered by the NCAA. 
Meeting this critical need for parent programming within intercollegiate sport is, however, challenged by the limited breadth of the current empirical literature on this topic (e.g., Dorsch et al., 2016a, 2016b; Parietti, Sutherland, \& Pastore, 2017). Moreover, the samples of this research have been exclusively Division I SAs, who only represent $32 \%$ of all NCAA SAs (NCAA, 2018), which reduces the generalizability of this work. While the NCAA has issued enlightening reports on Division I, II, and III SAs' social environments and college experiences (NCAA, 2016, 2017b), these nonperiodical reports are purely descriptive, were not designed to include inferential statistics assessing group differences by division, and often aggregate across divisions with regard to items assessing parenting. It is thus unknown if parental involvement and its links to SAs' experiences generalize to Division II and III. This data is vital for informing the development of effective programming for parents of SAs, as it would ensure the provision of ecologicallyvalid recommendations for best parenting practices that are tailored to the inherent organization of the NCAA. In short, without knowing if parenting is different across NCAA Divisions, any resulting education program may have null or even harmful effects because this preexisting population characteristic has not been accounted for (Powell, 2005). Thus, the primary aim of the present study was to assess SAs' reports of parental involvement at NCAA Division, I, II, and III institutions and explore if links between involvement and a range of SA experiences (i.e., academic self-efficacy, athletic satisfaction, well-being, and individuation) varied by division.

\section{Theoretical Frameworks for Parental Involvement in Intercollegiate Athletics}

The present study was grounded in complementary theoretical frameworks from sport psychology (Côté, 1999; Côté, Baker, \& Abernethy, 2007; Wylleman \& Lavallee, 2004; Wylleman, De Knop, Verdet, \& Cecič-Erpič, 2007) and developmental psychology (Arnett, 2015). We also drew upon research and theory that conceptualizes the construct of parental involvement during emerging adulthood (Fingerman \& Yahiurin, 2015; Lowe \& Dotterer, 2017).

In sport psychology, Côté and colleagues' developmental model of sport participation (Côté, 1999; Côté et al., 2007) and Wylleman and colleagues' lifespan model of the athletic career (Wylleman \& Lavallee, 2004; Wylleman et al., 2007) emphasize the roles of significant others (e.g., coaches, parents) in promoting positive and sustained sport participation. Parents are viewed as central to assuring these outcomes, and changes in their involvement from direct (e.g., enrolling children in sport) to indirect strategies (e.g., providing emotional support) across stages of a sport career are encouraged. Importantly, if individuals transition to the elite, college-level stage (i.e., "investment" or "mastery" stage), these models note that parents must transform from a leadership role (e.g., initiating interest in sport, providing the means to partake in many sports) to an emotionally supportive role (e.g., providing sport career advice, encouraging resilience to overcome setbacks such as injury) to harness the most successful and enjoyable sport experience.

In developmental psychology, emerging adulthood (Arnett, 2015) is recognized as the period that connects the end of adolescence and the beginning of 
young adulthood (ages 18-29). Originally established via a landmark paper by Arnett (2000), the field of emerging adulthood has since rapidly expanded and is flourishing with contributions from prominent scholars (e.g., Nelson \& Barry, 2005; Settersten, 2012). Collectively, this work has evidenced that delays in achieving the traditional criteria for adulthood (e.g., marriage, parenthood) in the 21 st century led to a distinct shift in the experiences of those in their twenties, a decade which now offers the ability to explore life opportunities before committing to adult responsibilities (Arnett, 2015). Importantly, emerging adulthood is characterized by the key features of identity explorations, self-focus, instability, optimism, and feeling in-between. Because this life stage is typified by uncertainty, scholars argue that parents remain key socialization agents to facilitate emerging adults' gradual gains in autonomy (e.g., Aquilino, 2006; Settersten, 2012). However, sustained parental connection can also challenge the balance between parents' involvement and autonomy support. This challenge is important in the present study, as SAs and parents may be prone to experience difficulty balancing involvement due to parents' long-term engagement in their children's sport careers.

The construct of parental involvement is proposed as multidimensional, consisting of parental support giving, contact, and academic engagement, to best fit the developmental stage of emerging adulthood and the educational context of college (Lowe \& Dotterer, 2017). These dimensions of involvement are appropriate as they reflect "more indirect strategies that support emerging adults' growing self-sufficiency, bridge the geographic distance that often accompanies living on-campus, and respect the independent functioning of the college system" (Lowe \& Dotterer, 2017, p. 30). The present study adopts this multidimensional definition and adds parental athletic engagement as a fourth involvement strategy given sport is a primary context within which parents of SAs are involved (e.g., Côté, 1999). Parental support giving is the provision of tangible (e.g., financial, practical) and nontangible (e.g., emotional, advice) support (e.g., Fingerman \& Yahiurin, 2015). Parental contact is the frequency with which parents and emerging adults communicate using various modes of contact, including in-person and technology-facilitated communication (e.g., Lefkowitz, Vukman, \& Loken, 2012). Parental academic engagement is the degree to which parents are interested and actively involved in their college student's academic lives, including discussing course grades and material (e.g., Wolf, Sax, \& Harper, 2009). Parental athletic engagement is the degree to which parents are interested and actively involved in their college SA's sport careers, including listening to their child about sportrelated problems and respecting decisions about sport careers (e.g., Dorsch et al., 2016b).

Ultimately, the transition to college is marked by parent-child relationships that become more mutual and intimate (e.g., viewing each other as near-equals and friends, experiencing less conflict and more warmth; Aquilino, 2006; Arnett, 2015), as well as involvement strategies that become more indirect (e.g., providing emotional support, texting; Fingerman \& Yahiurin, 2015; Lowe \& Dotterer, 2017). These changes support adaptive developmental outcomes for emerging adults. In bringing these theoretical frameworks together, it is our position that parents play a vital role in fostering positive athletic and developmental outcomes for NCAA SAs. 


\section{Research on Parental Involvement in Intercollegiate Athletics}

Dorsch et al. (2016a) were the first to utilize the four-part definition of parental involvement in intercollegiate sport in an effort to "provide evidentiary support for key parent involvement factors that are associated with NCAA student-athlete development" (p. 4). Results showed, for instance, that while moderate amounts of parental academic and athletic engagement facilitated athletic satisfaction, each domain of involvement negatively predicted individuation and altogether explained a significant proportion of variance in individuation (i.e., 34\%). Even though the sample was limited to Division I athletes, these initial findings helped operationalize parental involvement in intercollegiate sport as a multidimensional construct and revealed the role of parents in SA development. To maintain measurement consistency, the present study will define involvement as being composed of parental support, contact, academic engagement, and athletic engagement. Following is a review of research on each domain.

First, it is normative for parents to provide tangible and nontangible support to foster progress toward adulthood and to gradually reduce support as selfsufficiency is acquired (e.g., Fingerman \& Yahirun, 2015). Research on college SAs (e.g., Dorsch et al., 2016b) and elite, professional, and Olympic athletes (e.g., Wylleman et al., 2007) has revealed parental support to be prominent and of paramount importance for promoting positive outcomes. For instance, a descriptive report by the NCAA found about three-fourths of SAs across divisions said they "sometimes" or "often" asked their family for financial and emotional support (NCAA, 2017b). Interviews with SAs have also revealed that parental support facilitates success with integrating sport and school responsibilities (Cosh \& Tully, 2015). Importantly, stakeholders at the Division I level, including athletic administrators, coaches, and academic advisors, have stated that a fine line exists between providing appropriate support and too much support (Dorsch et al., 2016b; Parietti et al., 2017). These stakeholders characterized appropriate support as "fostering student-athletes' independence, facilitating the mission of the coaching staff and team, and being present to advocate for the student-athlete when necessary" (Dorsch et al., 2016b, p. 133), and too much support as behaviors that are intrusive and indulgent (e.g., imposing upon coaches' roles and decisions, contacting academic advisors about the SAs' problems with class schedules). While a grey area exists between appropriate and too much support, previous work found parental support strongly and negatively predicted Division I SAs' emotional and functional independence and attainment of adult criteria (Dorsch et al., 2016a).

Second, contact between parents and college students is frequent, as most students use cell phones to often communicate with their parents in the course of a week (e.g., Lefkowitz et al., 2012; Wolf et al., 2009). The cell phone is preferred because it enables direct and rapid contact despite geographic distance and because it provides an avenue to share experiences and garner support without infringing upon emerging adults' independence (e.g., Chen \& Katz, 2009). Research with SAs has yielded similar findings (e.g., Parietti et al., 2017). About $40 \%$ of Dorsch and colleagues' (2016a) sample of Division I SAs reported texting with parents daily and about one-third chatted on the phone a few times a week. While the mode 
of contact was not specified, a descriptive report by the NCAA showed that the proportion of SAs reporting daily contact with parents was similar across divisions and ranged from $43 \%$ to $73 \%$, depending on the sport (NCAA, 2016). It is noteworthy to mention that despite the popularity of online communication technology, about 50\% of SAs in Dorsch and colleagues' (2016a) study did not use email, social media, or video chatting to contact parents. Also, only about $25 \%$ saw their parents in person every few months. Given Division I athletic administrators, coaches, and staff have asserted that the instant communication allowed by cell phones has prompted overinvolvement (Dorsch et al., 2016b) and that parental contact has been negatively linked to Division I SAs' emotional independence (Dorsch et al., 2016a) and heavy drinking behaviors (Turrisi, Mastroleo, Mallett, Larimer, \& Kilmer, 2007), it seems there is also a balance to strike with appropriate parental contact.

Third, college students report their parents are appropriately engaged in their academic lives via inquiring about academic performance and learning (e.g., Wolf et al., 2009; Harper, Sax, \&Wolf, 2012). For example, Wolf et al. (2009) found that about $71 \%$ of the 10,760 college students sampled rated their parents as minimally involved in course selection decisions, which led the researchers to concluded that most students "view their parents as supportive of their academic endeavors" and "generally do not view them as encroaching on their academic decision making in college (Wolf et al., 2009, p. 346)." Research with SAs reveals similar findings (e.g., Dorsch et al., 2016a). For instance, a broad, descriptive report by the NCAA found $81 \%$ of SAs across divisions said their family was "appropriately involved" in their academics and about $65 \%$ of SAs "often" or "sometimes" asked family to assist with academic decisions (NCAA, 2017b). Interviews with SAs have also revealed that parents help ease the stress associated with poor academic performance (Cosh \& Tully, 2015) and serve as consultants for academic and career plans (Parietti et al., 2017). Notably, Dorsch et al. (2016a) found academic engagement positively predicted SAs' academic self-efficacy and athletic satisfaction and negatively predicted emotional and functional independence, reiterating the import of appropriate academic engagement.

Fourth, SAs report their parents are interested and actively engaged in their sport careers during college. For instance, Dorsch et al. (2016a) found that, on average, Division I SAs "agreed" their parents were athletically engaged, and Parietti et al. (2017) found all Division I SAs interviewed identified their parents as a key part of their athletic experiences and decisions. Likewise, a broad, descriptive report by the NCAA found that $79 \%$ of SAs across divisions said their family was "appropriately involved" in their athletics, with $17 \%$ reporting overinvolvement and 5\% reporting underinvolvement. Furthermore, about $71 \%$ noted asking family for advice on athletic issues "often" or "sometimes", including training and dealing with coaches (NCAA, 2017b). When asked to define appropriate involvement in intercollegiate sport, a head coach simply replied, "At the collegiate level, the parent needs to be a fan, because that is all the athlete really wants anyway" (Dorsch et al., 2016b, p. 129). This seems central to promoting the ideal SA experience, as Dorsch et al. (2016a) found parental athletic engagement bolstered Division I SAs' mental health and academic and sport outcomes; but, it also predicted lower levels of emotional independence. 


\section{The Present Study}

This literature validates our unified theoretical perspective of parental involvement in intercollegiate athletics by highlighting links between each aspect of the multidimensional construct of involvement in sport and SAs' experiences. Given the absence of Division II and III perspectives within this literature, future research is warranted to discover variability in involvement across divisions so as to accurately inform the development of education programs for parents of SAs (Powell, 2005). Adopting such an approach is integral to fostering positive athletic and developmental outcomes for NCAA SAs, especially as the familial expectation and pressure for sport achievement that is widespread in America (NCAA, 2016) does not align with the small proportion of individuals who become college and/or professional athletes (NCAA, 2017a). Focusing research and policy attention to helping parents learn how to be appropriately involved is therefore merited. As such, the present study was designed to descriptively assess involvement (i.e., support, contact, academic engagement, athletic engagement) and to investigate associations between involvement and SA experiences (i.e., academic self-efficacy, athletic satisfaction, well-being, and individuation) across NCAA divisions. Provided no research to date has assessed division-level differences in involvement and its links to SAs' experiences, we forwarded no a priori hypotheses.

\section{Method}

\section{Institutions and Participants}

The Division I (DI) institution included in this study is a large, public research university located in the Southwest United States, and sponsors 26 varsity sports and maintains enrollment around 98,000 students across its primary and regional campuses. Of these, 500 were SAs at the time of the present research. This school has produced 141 national championship teams and 372 individual national champions. The Division II (DII) institution included is a medium-sized, public university located in the Rocky Mountains region of the United States, and sponsors 15 varsity sports and maintains enrollment around 9,000 students. Of these, 350 were SAs at the time of the present research. This school has produced five national championship teams. The Division III (DIII) institution included is a small, private university located in the Northeast United States, and sponsors 17 varsity sports and maintains enrollment around 3,000 students. Of these, 333 were SAs at the time of the present research. This school has produced 20 conference championships.

A total of 455 SAs participated (38\% response rate), with relatively equal distribution across divisions, as $30 \%$ of the sample were DI SAs $(n=134), 37 \%$ were DII SAs $(n=170)$, and $33 \%$ were DIII SAs $(n=151)$. Demographically, $53 \%$ $(n=239)$ of the SAs were female, the overall sample ranged in age from 18 to 31 years $(M=19.81, S D=1.65)$, and $32 \%(n=144)$ identified as freshmen, $24 \%$ $(n=108)$ as sophomores, $22 \%(n=100)$ as juniors, and $22 \%(n=103)$ as seniors. Most $(81 \% ; n=365)$ identified their race as White or Caucasian, and the remaining SAs $(19 \% ; n=86)$ were collapsed into a minority category (i.e., $7 \%$ identified as Black or African American, 5\% as more than one race, 3\% as Asian, 3\% as other, 
and $1 \%$ as American Indian/Alaskan Native or Unknown). Four SAs declined to report their race. Parents of SAs represented a primarily married $(85 \%)$ and educated cohort of individuals; specifically, $10 \%$ of mothers and $16 \%$ of fathers completed education up to secondary school, $68 \%$ of mothers and $53 \%$ of fathers earned at least a bachelor's degree, and $22 \%$ of mothers and $31 \%$ of fathers earned an advanced degree ranging from a master's to a doctorate.

\section{Procedures}

Prior to the present study, the authorship team cultivated relationships with athletic department representatives at institutions that reflected diversity in terms of NCAA division and geographic location in the United States. Once institutional review boards at the three institutions approved the present study, respective athletic departments provided contact lists of all current SAs or agreed to distribute an online survey link to their current SAs. SAs were recruited in person or via an emailed flyer, and both formats informed SAs of the overarching study, the importance of their voluntary participation, and what their participation would entail. After recruitment, SAs were emailed an embedded link to a 110-item, online survey that took about $15 \mathrm{~min}$ to complete and remained active for 4 weeks to allow time to respond. Reminder emails were sent at the second and third weeks of data collection. Consent for participation was obtained via the initial page of the online survey. At the conclusion of the data collection period, 10 SAs from each university who completed at least $75 \%$ of the survey were randomly selected as $\$ 50$ gift card recipients.

\section{Measures Assessing Parental Involvement}

A modified version of the Social Support Resources index (Fingerman, Miller, Birditt, \& Zarit, 2009) was used to assess the frequency with which SAs $(1=$ Not at All to $7=$ Daily) received six types of parental support over the past few months: emotional, practical, social, advice, financial, and discussion of daily events. Mean scores were created so higher scores indicated more support $(\alpha=$ .83). Researchers using this scale with emerging adult (Fingerman et al., 2009) and college SA samples (Dorsch et al., 2016a) have also reported moderately strong reliability estimates ranging from .82 to .89 . To assess the frequency of parental contact, SAs reported how often $(1=$ Not at All to $7=$ Daily $)$ they communicated with their parents over the past few months via six contact modes (Wolf et al., 2009): in-person, e-mail, phone, texting, social media, and video chatting. Total sum scores were calculated so higher scores indicated more contact. Because this measure represented a total frequency count, regardless of the mode of contact $(\alpha=.53)$, it was retained. Researchers using this scale with a college SA sample also reported a moderately low reliability estimate $(\alpha=.53$; Dorsch et al., 2016a).

To assess parental academic engagement, SAs responded $(1=$ Strongly Disagree to $5=$ Strongly Agree) to four items from the University of California Undergraduate Experience Study (UCUES; Wolf et al., 2009). An example item was, "My parents are very interested in my academic progress", and mean scores were created so higher scores indicated more academic engagement $(\alpha=.73)$. 
Researchers using this scale with emerging adult (Wolf et al., 2009) and college SA samples (Dorsch et al., 2016a) also reported moderate reliability estimates ranging from .71 to .75 . To assess parental athletic involvement, SAs responded ( $1=$ Not at All True to $5=$ Very True) to a modified version of the 7-item Perceptions of Parents Scale (Niemiec et al., 2006). An example item was, "My parents try to understand how I see things in my sport", and mean scores were created so higher scores indicated more athletic engagement $(\alpha=.91)$. Researchers using this scale with a college SA sample also reported a strong reliability estimate $(\alpha=.93$; Dorsch et al., 2016a).

\section{Measures Assessing the Student-Athlete Experience}

Five items from the Academic Efficacy subscale of the Patterns of Adaptive Learning Scales (Midgley et al., 2000) were used to assess SAs' levels of academic self-confidence $(1=$ Not at All True to $5=$ Very True $)$. An example item was, "I can do even the hardest work in my classes if I try", and mean scores were created so higher scores indicated higher levels of academic self-efficacy $(\alpha=.90)$. Researchers using this scale with emerging adult (Reeve, 2013) and college SA samples (Dorsch et al., 2016a) also reported strong reliability estimates ranging from .88 to .93. The six-item Competition Satisfaction Scale (Lochbaum \& Roberts, 1993) was used to asses SAs' levels of athletic satisfaction $(1=$ Strongly Disagree to $6=$ Strongly Agree). An example item was, "I feel great/ proud of my sport outcomes", and mean scores were created so higher scores indicated higher levels of athletic satisfaction $(\alpha=.85)$. Researchers using this scale with a college SA sample also reported a moderately strong reliability estimate ( $\alpha=.83$; Dorsch et al., 2016a).

SA well-being was indicated by measures assessing depression and engagement in risky behaviors. The 11-item Center for Epidemiological Studies-Depression Scale (CES-D; Kohout, Berkman, Evans, \& Cornoni-Huntley, 1993) was used to assess how often SAs experienced depressive symptoms over the past week, such as loneliness and poor appetite. Items were rated on a Likert scale that ranged from 0 (Rarely or None of the Time [less than 1 day]) to 3 (Most or All of the Time [5-7 days]), and some items were reverse scored so that total summed scores represented higher levels of depression $(\alpha=.86)$. Researchers using this scale with emerging adult (Wei, Russell, \& Zakalik, 2005) and college SA samples (Dorsch et al., 2016a) also reported moderately strong reliability estimates ranging from .83 to .93. To assess the frequency with which SAs engaged in risky behaviors over the past month $(0=$ None to $6=$ Daily), six items from the Monitoring the Future Study (Bachman, Johnston, O’Malley, \& Schulenberg, 1996) and the National Longitudinal Study of Adolescent Health (Add Health; Udry, 1998) were used. Three domains of risky behaviors were assessed, including sexual activity (e.g., "Had sexual intercourse with more than one partner"), drinking (e.g., "Engaged in binge drinking [4-5 drinks on one occasion]"), and drug use (e.g., "Used marijuana"). Total sum scores were created so higher levels represented higher levels of risky behaviors. The internal consistency of scores was low $(\alpha=.54)$, but, because this measure represented a total frequency count regardless of the type of risky behavior and because we aimed to assess the association between involvement and overall risky behaviors rather than specific risky behaviors, it was retained as a total 
frequency score. Researchers using this scale with a college SA sample also reported a moderately low reliability estimate $(\alpha=.45$; Dorsch et al., 2016a).

SA individuation was indicated by measures assessing emotional independence, functional independence, and attainment of criteria for adulthood. Emotional (17-items) and functional (13-items) independence were assessed with a scale by Hoffman (1984). Emotional independence items reflected how much SAs felt free from excessive need for their parents' approval and closeness (e.g., "Being away from my parents makes me feel lonely"), and functional independence items reflected how much SAs felt free from reliance upon their parents for practical support and advice (e.g., "I consult with my parent(s) when deciding about parttime employment"). All items were reverse scored and rated on a Likert scale that ranged from 1 (Not at All True of Me) to 5 (Very True of Me). Mean scores were created so higher scores indicated higher levels of emotional and functional independence $(\alpha=.91$ for each scale). Researchers using this scale with emerging adult (Kenyon \& Koerner, 2009) and college SA samples (Dorsch et al., 2016a) also reported a moderately strong reliability estimates ranging from .75 to .92 .

SAs also reported the extent to which they had achieved the three criteria for adulthood: accepting responsibility for oneself, engaging in independent decisionmaking, and assuming financial independence (Arnett, 2015). To improve upon the 3 -point response scale $(1=N o, 2=$ In Some Respects Yes, and In Some Respects No, $3=Y e s)$ that is the traditional format, we used an extended Likert response scale that ranged from 1 (Strongly Disagree) to 5 (Strongly Agree). Mean scores were created so higher scores indicated higher levels of attainment of adult criteria. Our response scale achieved a higher level of internal consistency $(\alpha=.76)$ than previous studies that employed the 3-point scale (Kins, Soenens, \& Beyers, 2012; $\alpha$ range $=.36-.44 \mathrm{~s})$. Furthermore, researchers using this scale with a college SA sample also reported a moderate reliability estimate $(\alpha=.66$; Dorsch et al., 2016a).

\section{Data Analysis}

To achieve our first aim, descriptive statistics of the four parental involvement variables were examined. Group difference tests (i.e., $t$-test, ANOVAs with Tukey's honestly significant difference [HSD]) were conducted to determine whether there were mean level differences in involvement by division, as well as the categorical control variables (i.e., SA sex, race, and academic classification).

To achieve our second aim, hierarchical multiple linear regression analyses were conducted to first test if the four parental involvement variables predicted each of the seven outcomes related to SAs' experiences, after controlling for key SA demographic variables. Then, we tested if the main effects of involvement on SAs' experiences were moderated by NCAA Division. Interaction terms were created between each mean-centered involvement variable and two dummy variables that represented contrasts between DI and DIII and DI and DII (DI = referent group). Demographic control variables were SA division, sex (male $=0$, female $=1$ ), race/ethnicity (White $=0$, minority $=1$ ), academic classification, parent education level, and high school grade point average (HSGPA; only included in academic self-efficacy models). These controls were selected based on previous work identifying them as correlates of involvement and SAs' athletic and 
developmental outcomes (e.g., Dorsch et al., 2016a; Fingerman \& Yahirun, 2015; NCAA, 2016, 2017a, 2017b). To preserve parsimony and reduce model saturation, SA classification (i.e., freshman to senior) was mean centered so it referred to the "average" class. Parent education level was indicated by the mean of mothers' and fathers' highest education levels $(M=6.56, S D=1.42)$, which ranged from elementary school to doctorate degree, and a score of 7 indicated a bachelor's degree. Three regression models were tested for each outcome related to the SA experience. Step 1 included the demographic controls, step 2 added the four parental involvement variables, and step 3 added the eight interaction terms. Incremental $F$-tests were used to assess whether $\Delta R^{2}$ across models was significant. Nonsignificant interactions were dropped from respective models and significant interactions were probed by examining the significance of the simple slope for the involvement-outcome association for each division (Aiken \& West, 1991).

\section{Results}

\section{Descriptive Statistics}

Univariate statistics for nearly all continuous study variables revealed normal distributions and moderate to high levels of internal consistency (see Table 1). Correlation results showed parental support, contact, academic engagement, and athletic engagement were all significantly positively correlated. These moderate effect sizes $(r=.31-.54)$ suggest the four variables altogether represented parental involvement in the lives of SAs across NCAA Divisions. All four involvement variables were positively correlated with athletic satisfaction and negatively correlated with depression and emotional and functional independence (Table 1).

On average, SAs received support from parents "a few times a month" and communicated with parents "once a month" (Table 2). Collapsing across responses, $60 \%$ of SAs received support from parents at least once a week and 36\% talked with their parents at least once a week. SAs also reported moderately high average levels of parental academic and athletic engagement. About $85 \%$ and $94 \%$ "agreed" or "strongly agreed" that their parents were engaged in their academic and athletic lives, respectively. Item-level statistics for support showed that while about $31 \%$ of SAs did not receive socializing support from parents, $73 \%$ received emotional support at least once a week. Item-level statistics for contact showed that email, social media, and video chatting were unpopular contact modes; rather, 58\% and $76 \%$ of SAs talked with their parents via phone or texting at least "a few times a week", respectively. About 55\% saw their parents in person "once every few months" to "a few times a month" (Table 2).

SAs reported moderately high average levels of academic self-efficacy and athletic satisfaction (Table 3). About 65\% reported a high level of academic selfefficacy was "very true" of them and 52\% "agreed" they were satisfied with their athletic performance. Average levels of SA well-being indicated depressive symptoms were experienced 1-2 days in the past week and engaging in risky behaviors almost never occurred. About $78 \%$ of SAs reported feeling depressed "some of the time (1-2 days/past week)" and 97\% did not engage or rarely engaged in risky behaviors. SAs reported moderately average levels of individuation, and 


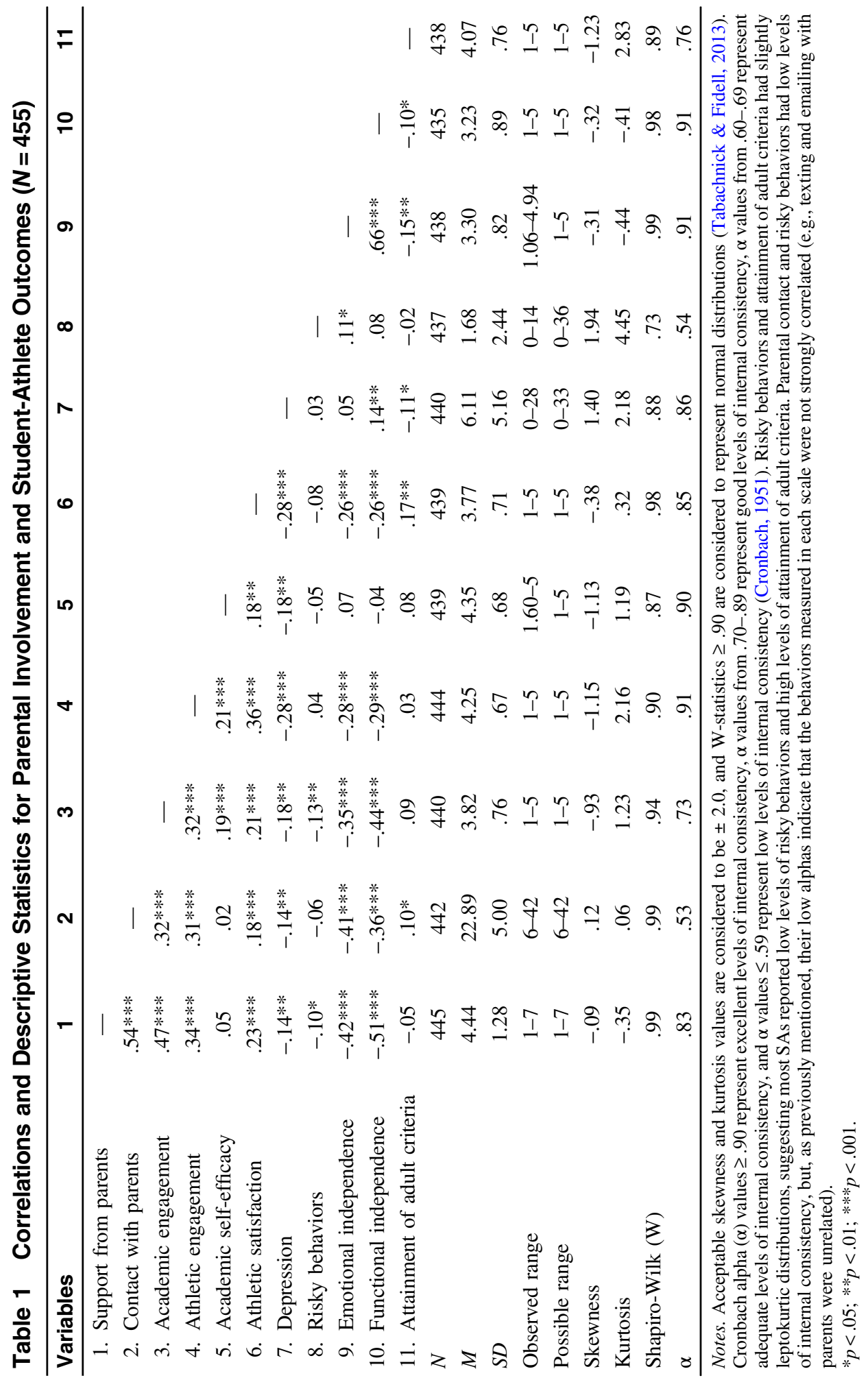




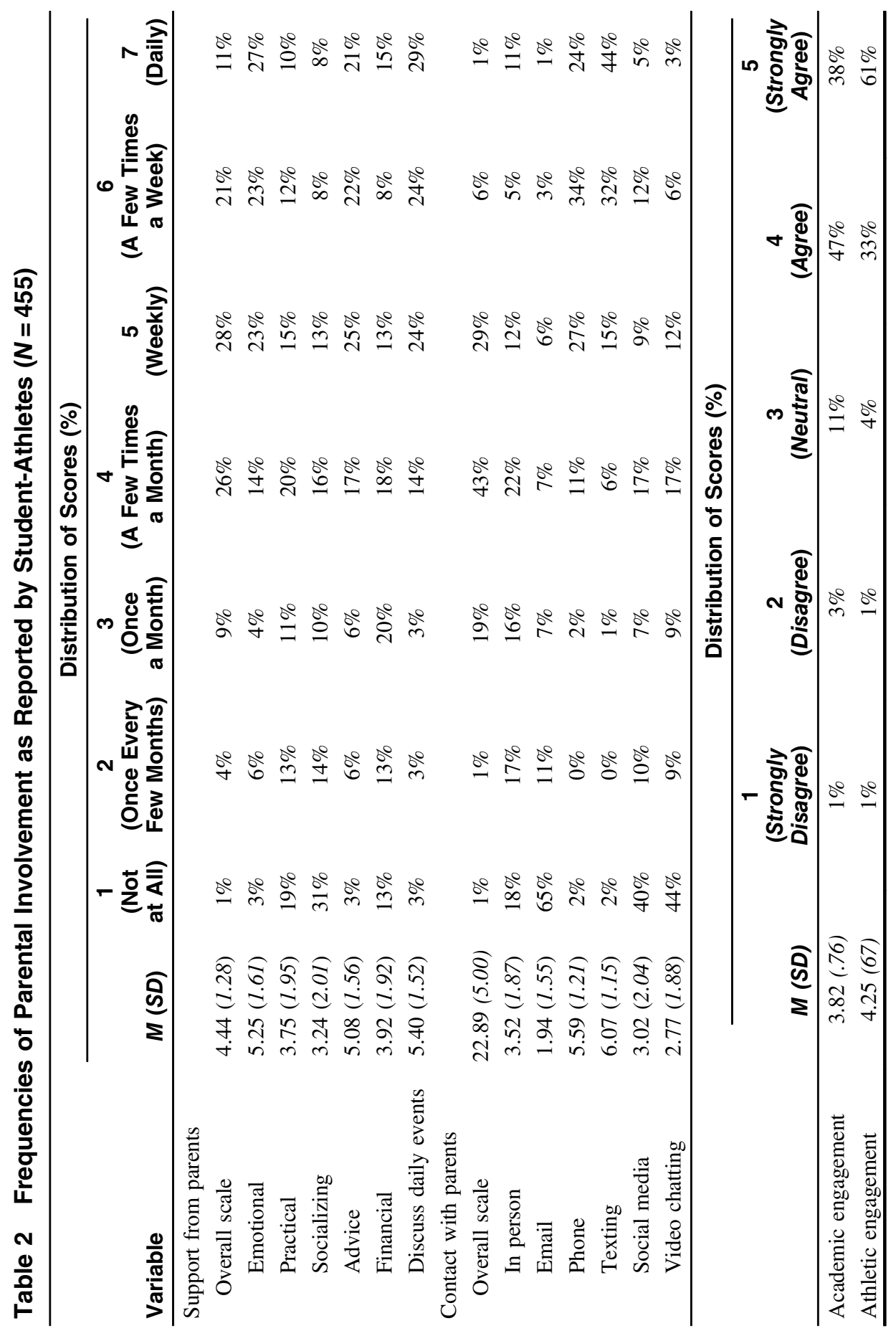


$44 \%$ and $34 \%$, respectively, reported emotional and functional independence was "quite a bit true of me." About 45\% "agreed" they had attained the criteria necessary for adulthood (Table 3 ).

There were division differences in four outcomes related to the SA experience: (a) athletic satisfaction was higher in DII than DIII SAs; (b) risky behaviors were higher in DIII than DII and DI SAs; (c) emotional independence was higher in DIII than DII and DI SAs; and (d) functional independence was higher in DI and DIII SAs compared to DII SAs (Table 4). Further, male SAs reported higher levels of risky behaviors compared to females and White SAs reported higher levels of emotional independence than minority SAs. Last, junior and senior SAs reported higher levels of risky behaviors compared to freshmen, and senior SAs engaged in more risky behaviors than sophomores. The effect sizes for all these group differences were small (i.e., differences occurred within the same response level) and should be interpreted with caution.

\section{Group Differences in Parental Involvement}

Results revealed no differences in average levels of parental support, contact, academic engagement, and athletic engagement across NCAA divisions (Table 5). Female SAs reported higher levels of contact and lower levels of academic engagement compared to males. Freshmen SAs reported the highest levels of support and contact, and also reported more academic engagement than juniors. There were no racial/ethnic differences in involvement. The effect sizes for these differences were small (i.e., differences occurred within the same response level) and should be interpreted with caution.

\section{Predicting Outcomes Related to SAs' Experiences from Parental Involvement}

Overall regression analyses revealed the set of interaction terms added in Step 3 did not explain additional variance in any outcomes related to SAs' experiences. Furthermore, none of the individual interaction terms were significant predictors of any outcomes, with one exception: risky behaviors. We thus abided by Aiken and West's (1991) step-down procedures and only interpreted and reported the findings for Model 2, the main effects of parental involvement, for each outcome (sans risky behaviors).

Academic self-efficacy. The overall model predicting SA academic self-efficacy from the demographic control variables was not significant and only explained about $1 \%$ of variance in academic self-efficacy. The addition of the four parental involvement variables explained a significant amount of variance beyond the controls, $F$ for $\Delta R^{2}(4,407)=7.57, p<.001$. The overall model explained about $8 \%$ of variance in academic self-efficacy. Parental academic and athletic engagement were significant positive predictors, such that for every one-unit increase in parents' academic and athletic engagement, SAs' reports of academic self-efficacy increased by .16 and .19 points, respectively (Table 6).

Athletic satisfaction. The overall model predicting SA athletic satisfaction from the demographic control variables was not significant and only explained about $2 \%$ 


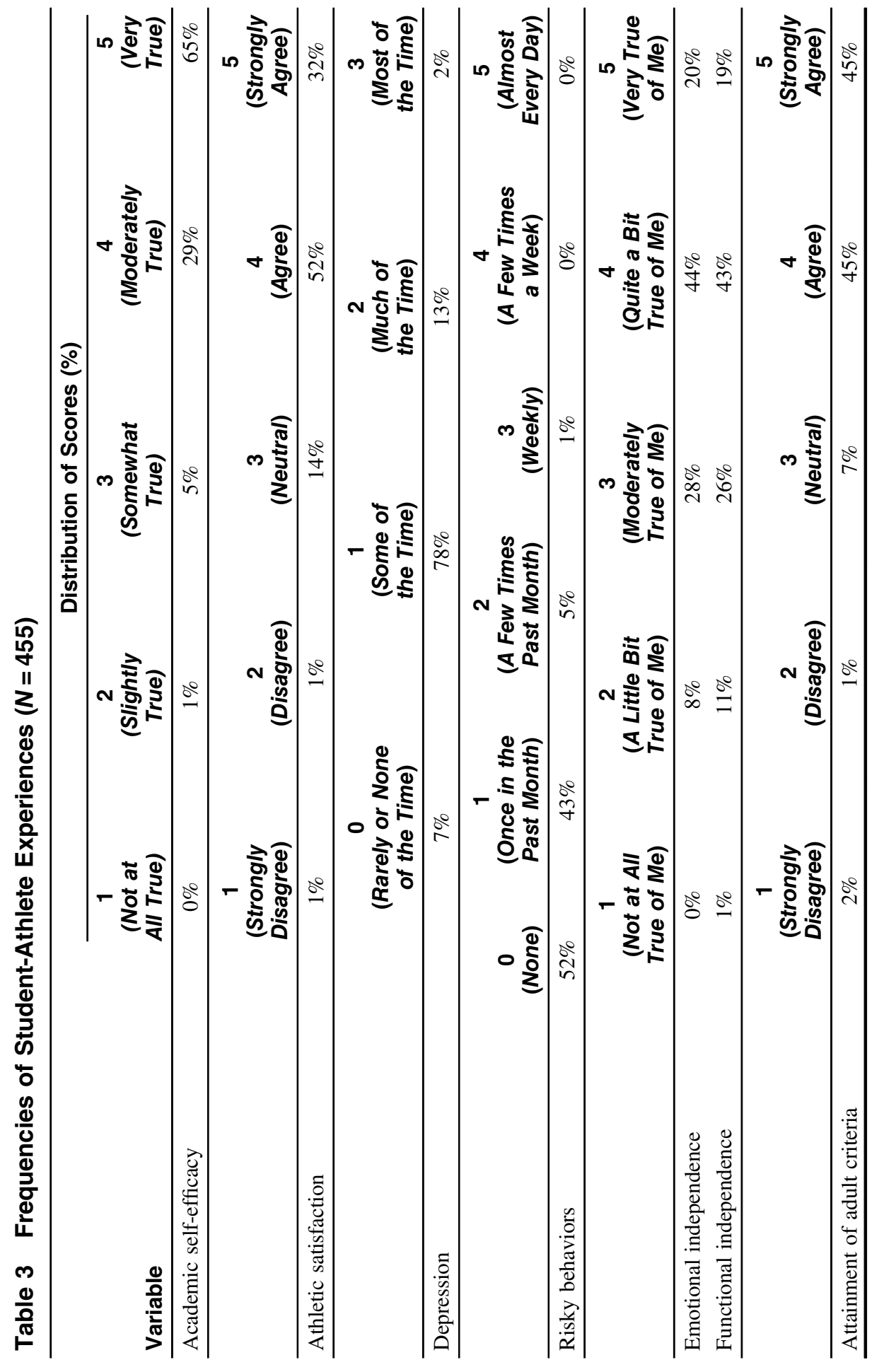


Table 4 Group Differences in Student-Athletes' Experiences by NCAA Division and Student-Athlete Gender, Race/Ethnicity, and Academic Class

\begin{tabular}{|c|c|c|c|c|c|c|c|}
\hline \multirow{2}{*}{$\begin{array}{l}\text { Student-Athlete } \\
\text { Experiences }\end{array}$} & \multicolumn{5}{|c|}{ NCAA Division } & \multirow{2}{*}{\multicolumn{2}{|c|}{$F\left(d f^{n}, d f^{d}\right)$}} \\
\hline & \multicolumn{2}{|c|}{ Division I } & \multicolumn{2}{|c|}{ Division II } & Division III & & \\
\hline Academic self-efficacy & \multicolumn{2}{|c|}{$4.36(.66)$} & \multicolumn{2}{|c|}{$4.25(.76)$} & $4.44(.58)$ & \multicolumn{2}{|l|}{ ns } \\
\hline Athletic satisfaction & \multicolumn{2}{|c|}{$3.76(.74)$} & \multicolumn{2}{|c|}{$3.88(.74)^{\mathrm{c}}$} & $3.65(.63)$ & \multicolumn{2}{|c|}{$3.83 *(2,436)$} \\
\hline Depression & \multicolumn{2}{|c|}{$6.34(5.19)$} & \multicolumn{2}{|c|}{$6.42(5.50)$} & $5.58(4.72)$ & \multicolumn{2}{|l|}{$n s$} \\
\hline Risky behaviors & \multicolumn{2}{|c|}{$1.39(1.86)^{\mathrm{b}}$} & \multicolumn{2}{|c|}{$1.26(2.01)^{\mathrm{c}}$} & $2.36(3.09)$ & \multicolumn{2}{|c|}{$9.40 * * *(2,434)$} \\
\hline Emotional independence & \multicolumn{2}{|c|}{$3.29(.83)^{\mathrm{b}}$} & \multicolumn{2}{|c|}{$3.07(.85)^{\mathrm{c}}$} & $3.56(.72)$ & \multicolumn{2}{|c|}{$14.23 * * *(2,435)$} \\
\hline Functional independence & \multicolumn{2}{|c|}{$3.25(.90)^{\mathrm{a}}$} & \multicolumn{2}{|c|}{$2.96(.90)^{\mathrm{c}}$} & $3.49(.77)$ & \multicolumn{2}{|c|}{$14.57 * * *(2,432)$} \\
\hline \multirow[t]{3}{*}{ Attainment of adult criteria } & $4.11(.63)$ & & 4.07 & $(.94)$ & $4.02(.64)$ & $n s$ & \\
\hline & \multicolumn{3}{|c|}{ Gender } & & \multicolumn{2}{|c|}{ Race/Ethnicity } & \multirow[b]{2}{*}{$t(d f)$} \\
\hline & Male & & male & $t(d f)$ & White & Minority & \\
\hline Academic self-efficacy & $4.34(.72)$ & & $5(.63)$ & $n s$ & $4.35(.66)$ & $4.31(.74)$ & $n s$ \\
\hline Athletic satisfaction & $3.83(.73)$ & & $1(.69)$ & $n s$ & $3.75(.69)$ & $3.81(.80)$ & $n s$ \\
\hline Depression & $5.88(5.52)$ & 6.3 & $(4.82)$ & $n s$ & $6.13(5.26)$ & $6.06(4.68)$ & $n s$ \\
\hline Risky behaviors & $2.20(2.84)$ & 1.2 & $3(1.94)$ & $\begin{array}{c}4.12^{\mathrm{a} * * *} \\
(347)\end{array}$ & * $1.60(2.52)$ & $2.06(2.03)$ & $n s$ \\
\hline Emotional independence & $3.37(.79)$ & & $4(.85)$ & $n s$ & $3.35(.79)$ & $3.08(.94)$ & $\begin{array}{r}2.35^{\mathrm{a} *} \\
(107)\end{array}$ \\
\hline Functional independence & $3.16(.90)$ & & $9(.87)$ & $n s$ & $3.23(.88)$ & $3.21(.91)$ & $n s$ \\
\hline Attainment of adult criteria & $4.10(.85)$ & & $3(.68)$ & $n s$ & $4.04(.79)$ & $4.19(.65)$ & $n s$ \\
\hline
\end{tabular}

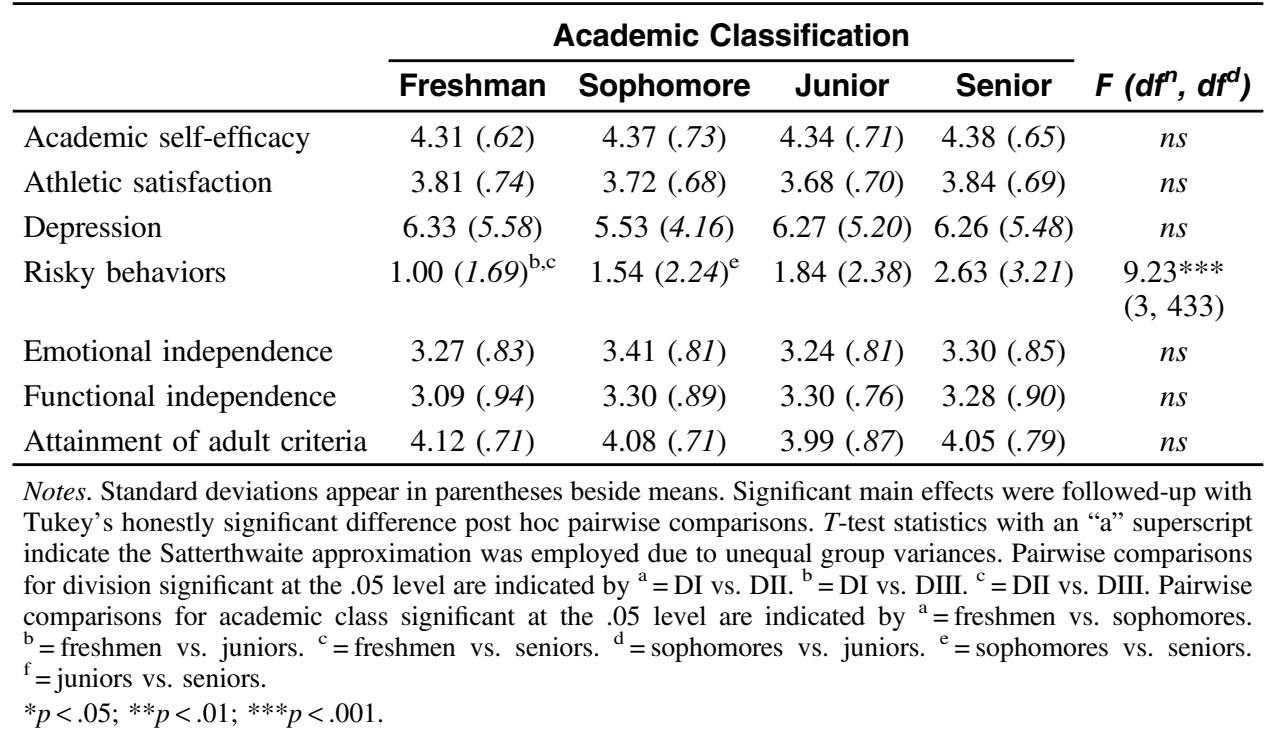




\section{Table 5 Group Differences in Parental Involvement by NCAA Division and Student-Athlete Gender, Race/Ethnicity, and Academic Class}

\begin{tabular}{|c|c|c|c|c|c|c|c|}
\hline \multirow{2}{*}{ Parental Involvemen } & \multicolumn{7}{|c|}{ NCAA Division } \\
\hline & \multicolumn{2}{|c|}{ Division I } & \multicolumn{2}{|c|}{ Division II } & Division III & \multicolumn{2}{|c|}{$F\left(d f^{n}, d f^{d}\right)$} \\
\hline Support from parents & \multicolumn{2}{|c|}{$4.26(1.31)$} & \multicolumn{2}{|c|}{$4.61(1.33)$} & $4.42(1.18)$ & \multicolumn{2}{|c|}{$n s$} \\
\hline Contact with parents & \multicolumn{2}{|c|}{$22.48(5.01)$} & \multicolumn{2}{|c|}{$23.10(5.24)$} & $23.02(5.33)$ & \multicolumn{2}{|c|}{$n s$} \\
\hline Academic engagement & \multicolumn{2}{|c|}{$3.73(.77)$} & \multicolumn{2}{|c|}{$3.89(.75)$} & $3.81(.75)$ & \multicolumn{2}{|c|}{$n s$} \\
\hline \multirow[t]{3}{*}{ Athletic engagement } & $4.20(.6$ & & 4.27 & $(.71)$ & $4.27(.61)$ & & $n s$ \\
\hline & \multicolumn{2}{|c|}{ Gender } & \multirow{2}{*}{\multicolumn{2}{|c|}{$t(d f)$}} & \multicolumn{2}{|c|}{ Race/Ethnicity } & \multirow[b]{2}{*}{$t(d f)$} \\
\hline & Male & Female & & & White & Minority & \\
\hline Support from parents & $4.37(1.41)$ & $4.50(1.16)$ & & $n s$ & $4.42(1.27) 4$ & $4.50(1.33)$ & $n s$ \\
\hline Contact with parents & $22.10(5.49)$ & $23.57(4.84)$ & -2.9 & $9 * *(440) 23$ & $23.02(5.07) 2$ & $22.41(5.78)$ & $n s$ \\
\hline Academic engagement & $3.92(.74)$ & $.73(.76)$ & 2.72 & $2 * *(438)$ & $3.84(.74) \quad 3.7$ & $.73(.82)$ & $n s$ \\
\hline Athletic engagement & $4.28(.66)$ & $.22(.67)$ & & $n s$ & $4.24(.64) \quad 4.2$ & $.25(.76)$ & $n s$ \\
\hline & & Academic & c Clas & ssification & & & \\
\hline & Freshman & Sophom & more & Junior & Senior & $F\left(d f^{n}\right.$, & $\left.d f^{d}\right)$ \\
\hline Support from parents & $4.79(1.26)^{\mathrm{a}, \mathrm{b}, \mathrm{c}}$ & $4.28(1$. & $.20)$ & $4.24(1.29)$ & $4.33(1.32)$ & $5.19 * *(3$ & $3,441)$ \\
\hline Contact with parents & $24.47(5.32)^{\mathrm{a}, \mathrm{b}, \mathrm{c}}$ & c $22.10(4$ & 4.83) & $22.22(5.21)$ & l) 22.18 (4.95) & $6.51 * *$ & $3,438)$ \\
\hline Academic engagement & $3.97(.65)^{\mathrm{b}}$ & $3.84(.7$ & 79) & $3.67(.85)$ & $3.75(.72)$ & $3.41 *(3$ & $3,436)$ \\
\hline Athletic engagement & $4.23(.65)$ & $4.27(.6$ & 69) & $4.21(.75)$ & $4.28(.57)$ & $n s$ & \\
\hline
\end{tabular}

Notes. Standard deviations are in parentheses beside means. Significant main effects were followed-up with Tukey's honestly significant difference post hoc pairwise comparisons. Comparisons significant at the .05 level are indicated by ${ }^{\mathrm{a}}=$ DI vs. DII. ${ }^{\mathrm{b}}=$ DI vs. DIII. ${ }^{\mathrm{c}}=$ DII vs. DIII.

$* p<.05 ; * * p<.01 ; * * * p<.001$.

of variance in athletic satisfaction. Adding the four parental involvement variables explained a significant amount of variance beyond the controls, $F$ for $\Delta R^{2}(4,416)=$ $18.26, p<.001$. The overall model explained about $17 \%$ of variance in athletic satisfaction. Parental athletic engagement was the sole significant involvement predictor and explained about $8 \%$ of unique variance in athletic satisfaction. These results revealed that for every one-unit increase in parents' athletic engagement, SAs' reports of satisfaction with sport increased by .31 points (Table 6).

Well-being. The overall model predicting SA depression from the demographic control variables was not significant and only explained about $1 \%$ of variance in depression. The addition of the four parental involvement variables explained a significant amount of variance beyond the controls, $F$ for $\Delta R^{2}(4,417)=10.47$, $p<.001$. The overall model explained about $10 \%$ of variance in depression. Parental athletic engagement was the only significant involvement predictor and explained about $6 \%$ of unique variance in depression. Specifically, for every one-unit increase in parents' athletic engagement, SAs' reports of feeling depressive symptoms over the past week decreased by about 1.85 points (Table 6). 


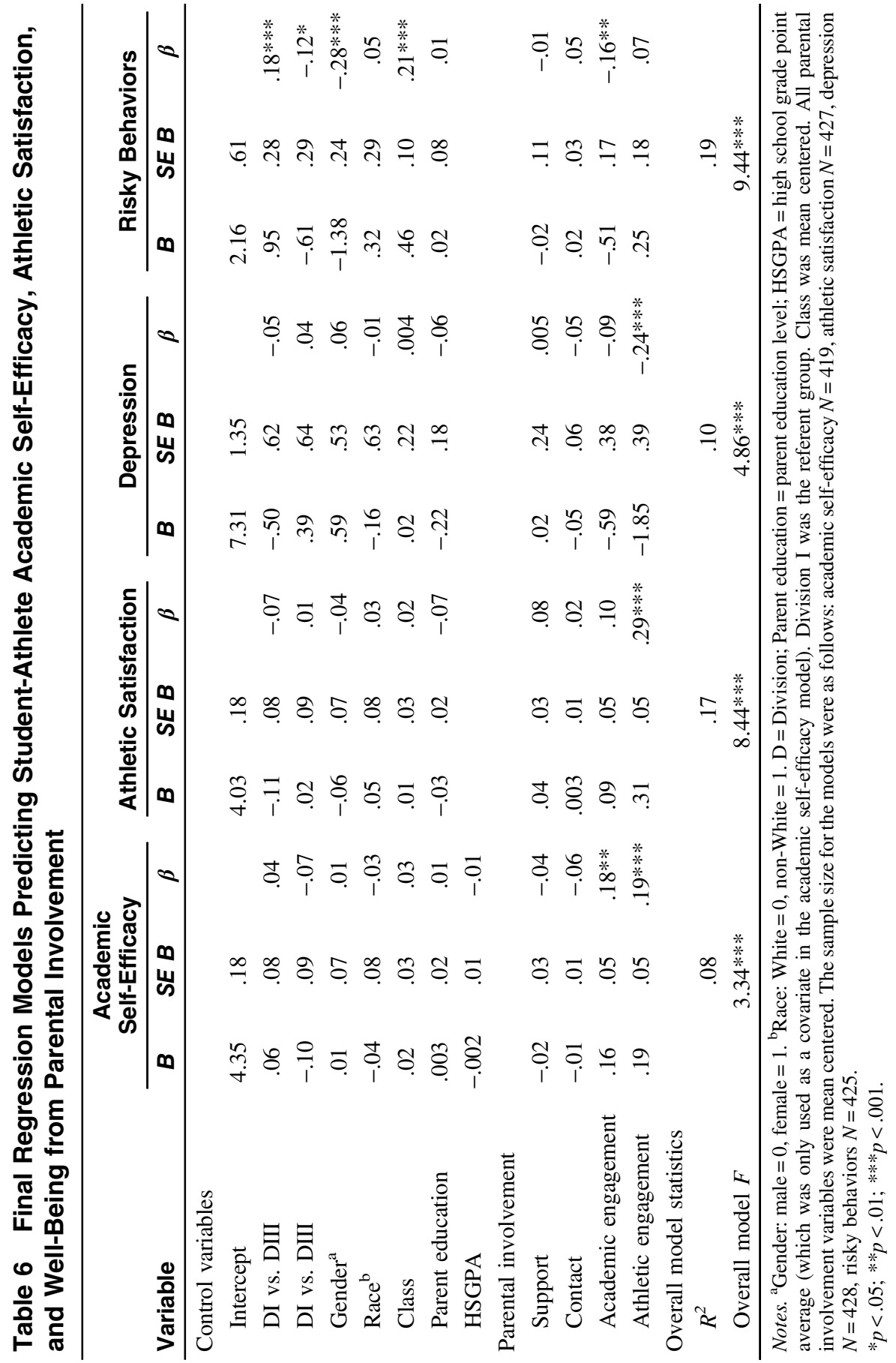


The overall model predicting SA risky behaviors from the demographic control variables was significant and explained about $16 \%$ of variance in risky behaviors. SA division, gender, and class were significant and revealed that DI SAs reported lower mean levels of risky behaviors than DIII SAs, and higher mean levels than DII SAs. Females reported lower mean levels of risky behaviors and increases in SA class predicted more risky behaviors. Adding the four parental involvement variables explained a significant amount of variance beyond the controls, $F$ for $\Delta R^{2}(4,414)=2.69, p<.05$. The overall model explained about $19 \%$ of variance in risky behaviors. Parental academic engagement was the sole significant involvement predictor and explained about $3 \%$ of unique variance in risky behaviors. For every one-unit increase in parents' academic engagement, SAs' risky behaviors over the past month decreased by about .51 points (Table 6).

Step 3 added the eight interaction variables, which as a set did not explain any additional variance in risky behaviors; but, one of the interaction terms was significant, revealing that the association between parental academic engagement and risky behaviors varied between DI and DII SAs, $\beta=-.17, p<.05$. Simple slope follow-up analyses found this link was not significant among DI SAs $(\beta=-.05$, $p=.63$ ), but was among DII SAs, $\beta=-.31, p<.001$. Specifically, for every oneunit increase in parents' academic engagement, DII SAs' reports of risky behaviors decreased by about 1.02 points. While this result is interesting, its effect size is small and should be interpreted with caution. Given this, along with the nonsignificance of the set of interactions, Model 2 represents the final results for risky behaviors (Table 6).

Individuation. The overall model predicting SA emotional independence from the demographic control variables was significant and explained about $11 \%$ of variance in emotional independence. SA division, gender, and race/ethnicity were significant. Specifically, DI SAs reported lower mean levels of emotional independence than DIII SAs and higher mean levels than DII SAs, and female and minority SAs reported lower mean levels of emotional independence. The addition of the four parental involvement variables explained a significant amount beyond the controls, $F$ for $\Delta R^{2}(4,415)=40.91, p<.001$. The overall model explained about $36 \%$ of variance in emotional independence, which is $25 \%$ more variance than Model 1. Notably, all four involvement variables were significant, negative predictors. For every one-unit increase in parents' support, contact, academic engagement, and athletic engagement, SAs' reports of emotional independence decreased by $.10, .03, .24$, and .12 points, respectively. Contact and academic engagement had the strongest associations, and each explained about $5 \%$ of unique variance in emotional independence (Table 7).

The overall model predicting SA functional independence from the demographic control variables was significant and explained about $7 \%$ of variance in functional independence. SA division was significant and showed that DI SAs reported lower mean levels of functional independence than DIII SAs, and higher mean levels than DII SAs. Adding the four parental involvement variables explained a significant amount of variance beyond the controls, $F$ for $\Delta R^{2}$ (4, $412)=48.25, p<.001$. The overall model explained about $37 \%$ of variance in functional independence, which is $30 \%$ more variance than Model 1. Parental support and academic engagement were significant, negative predictors. 


\section{Table 7 Final Regression Models Predicting Student-Athlete Individuation from Parental Involvement}

\begin{tabular}{|c|c|c|c|c|c|c|c|c|c|}
\hline \multirow[b]{2}{*}{ Variable } & \multicolumn{3}{|c|}{$\begin{array}{c}\text { Emotional } \\
\text { Independence }\end{array}$} & \multicolumn{3}{|c|}{$\begin{array}{c}\text { Functional } \\
\text { Independence }\end{array}$} & \multicolumn{3}{|c|}{$\begin{array}{l}\text { Attainment of } \\
\text { Adult Criteria }\end{array}$} \\
\hline & $B$ & SE B & $\bar{\beta}$ & $B$ & SE B & $\beta$ & $B$ & SE B & $\bar{\beta}$ \\
\hline \multicolumn{10}{|l|}{ Control variables } \\
\hline Intercept & 3.15 & .18 & & 3.22 & .19 & & 4.46 & .21 & \\
\hline DI vs. DIII & .32 & .08 & $.18 * * *$ & .30 & .09 & $.16^{* * *}$ & -.06 & .09 & -.04 \\
\hline DI vs. DII & -.15 & .09 & -.09 & -.15 & .09 & -.08 & -.08 & .10 & -.05 \\
\hline Gender $^{\mathrm{a}}$ & -.28 & .07 & $-.17 * * *$ & .03 & .08 & .02 & -.07 & .08 & .04 \\
\hline Race $^{b}$ & -.26 & .08 & $-.12 * *$ & -.02 & .09 & -.007 & .17 & .10 & .09 \\
\hline Class & -.07 & .03 & $-.09 *$ & -.01 & .03 & -.01 & -.02 & .03 & -.02 \\
\hline Parent education level & .04 & .02 & .08 & -.006 & .03 & -.01 & -.05 & .03 & -.10 \\
\hline \multicolumn{10}{|l|}{ Parental involvement } \\
\hline Support & -.10 & .03 & $-.15^{* *}$ & -.22 & .04 & $-.32 * * *$ & -.14 & .04 & $-.23 * * *$ \\
\hline Contact & -.03 & .01 & $-.22 * * *$ & -.02 & .008 & -.10 & .03 & .01 & $.18 * *$ \\
\hline Academic engagement & -.24 & .05 & $-.22 * * *$ & -.26 & .05 & $-.22 * * *$ & .15 & .06 & $.15^{* *}$ \\
\hline Athletic engagement & -.12 & .05 & $-.10 *$ & -.10 & .06 & -.07 & -.01 & .06 & -.01 \\
\hline \multicolumn{10}{|l|}{ Overall model statistics } \\
\hline$R^{2}$ & & .36 & & & .37 & & & .07 & \\
\hline Overall model $F$ & & $23.41 * * *$ & & & $24.11 * * *$ & & & $2.95 * *$ & \\
\hline
\end{tabular}

Notes. ${ }^{\mathrm{a}}$ Gender: male $=0$, female $=1 .{ }^{\mathrm{b}}$ Race: White $=0$, non-White $=1$. Division (D) I was the referent group. Class was mean centered. All parental involvement variables were mean centered. The sample size for the models were as follows: emotional independence $N=426$, functional independence $N=423$, and attainment of adult criteria $N=425$.

$* p<.05 ; * * p<.01 ; * * * p<.001$.

Specifically, for every one-unit increase in parents' support and academic engagement, SAs' reports of functional independence decreased by .22 and .26 points, respectively. Parental support had the strongest association and explained about $10 \%$ of unique variance in functional independence (Table 7).

The overall model predicting SA attainment of adult criteria from the demographic control variables was not significant and only explained about $2 \%$ of variance in adult criteria. The addition of the four parental involvement variables explained a significant amount of variance beyond the controls, $F$ for $\Delta R^{2}$ $(4,414)=5.33, p<.001$. The overall model explained about $7 \%$ of variance in adult criteria. Parental support, contact, and academic engagement were significant predictors. Specifically, for every one-unit increase in parents' support, SAs' attainment of adult criteria decreased by .14 points. Conversely, for every one-unit increase in parents' contact and academic engagement, SAs' attainment of adult criteria increased by .03 and .15 points, respectively. Parental support had the strongest association and explained about $5 \%$ of unique variance in adult criteria (Table 7). 


\section{Discussion}

Informed by the theories of emerging adulthood (e.g., Arnett, 2015) and sport career development (e.g., Côté, 1999), this study descriptively assessed parental involvement in intercollegiate sport from the perspective of SAs at Division I, II, and III member institutions and investigated whether associations between involvement and SAs' experiences varied by division. Foremost, we found no evidence for mean-level differences in parental involvement by NCAA division, indicating descriptive results for involvement may be interpreted with all divisions in mind. Given replication of our results with a broader sample of schools within each division is needed to support this preliminary conclusion, our novel key descriptive results revealed that (a) all four aspects of involvement were positively correlated, (b) SAs reported moderately high mean levels of parental support, contact, academic engagement, and athletic engagement, and (c) the distribution of involvement strategies revealed most SAs perceived their parents to be actively involved, but not overbearing. These results align with previous work with SA samples (e.g., Dorsch et al., 2016a) and extend it by characterizing involvement from the perspective of SAs across NCAA divisions. For instance, we found that texting is the primary means by which parents and SAs maintain contact, which typically occurs on a daily basis. Thus, despite different time demands for sport participation across divisions (NCAA, 2016), DI, DII, and DIII SAs altogether seem to rely on texting as an efficient tool to touch base with parents throughout their busy days. This finding serves as a clear and simple best practice to recommend within an education program for parents of SAs across divisions. Similarly, because most SAs in our study concurred their parents were engaged in their academic and athletic lives, it is reasonable to assume the most common topics of these texting conversations were school and sport. This conclusion is supported by research identifying parents as primary consultants for coping with and making decisions about academics and athletics (e.g., Cosh \& Tully, 2015; NCAA, 2017b). Following, another best practice to recommend is for parents to text with their SAs throughout the week to inquire about their sport and school endeavors.

Overall, our descriptive results reverberate findings from the broader literature on parental support, contact, and academic engagement during emerging adulthood (e.g., Lowe \& Dotterer, 2017; Fingerman \& Yahirun, 2015), suggesting SAs and their nonathlete peers are experiencing similar, moderate levels of parental involvement. This conclusion has implications for tempering popular media reports that have drawn attention to overinvolved parents in higher education (e.g., Bastie, 2017; Jafar, 2012), and instead convey that the majority of college students (including SAs) have parents who are appropriately and moderately involved. For instance, results from a national NCAA survey found about $81 \%$ of SAs reported their parents were "appropriately involved" across nine life domains (NCAA, 2017b). But, because about $11 \%$ of SAs reported their parents were "overly involved," and since our results showed, on average, about $12 \%$ of SAs did not receive any of the six types of support, there are nonnegligible proportions of SAs who experience over- and underinvolvement, respectively. This further confirms the need to develop interventions to leverage appropriate, positive involvement. Last, but not least, it is paramount to note 
there is accumulating evidence to validate parental involvement in intercollegiate sport as a multidimensional construct consisting of support, contact, academic engagement, and athletic engagement (Lowe \& Dotterer, 2017). Because our study and previous researchers (Dorsch et al., 2016a) both found that the correlations among the involvement strategies did not share a majority of variance to be considered the same measure, future researchers should continue to assess all four as distinct, but integral, components of parental involvement that is appropriate for the developmental stage of emerging adulthood and the context of intercollegiate sport. This last recommendation is especially critical, considering our results showed each involvement strategy had differential effects on SAs' experiences.

Regression analyses results showed the effect of parents' support, contact, academic engagement, and athletic engagement on outcomes related to SAs' experiences were similar across divisions. In combination with our descriptive results, these findings represent the first data supporting the idea that parental involvement, both average levels and associations with SAs' experiences, may be comparable across the intercollegiate spectrum. While replication of our results with a broader sample of schools within each division is required to support this preliminary conclusion, they remain an important resource for informing programs that have been (e.g., NCAA Mental Health Resources) and/or will be developed to support SA wellbeing and success in school and sport because they highlight parents as an integral component for a positive intercollegiate experience.

Overall, regression results showed that (a) academic and athletic engagement positively predicted academic self-efficacy, (b) athletic engagement positively predicted athletic satisfaction and negatively predicted depression, (c) academic engagement negatively predicted risky behaviors, (d) all aspects of involvement negatively predicted emotional independence, (e) support and academic engagement negatively predicted functional independence, and (f) support negatively predicted adult criteria while contact and academic engagement positively predicted adult criteria. Importantly, the strength and direction of these associations closely resemble those reported by Dorsch et al. (2016a) which altogether offers a clearer understanding of the contribution of parents to SAs' school, sport, and developmental outcomes. For instance, it is important to note that across both studies parental support had a moderately strong, negative association with and explained a significant proportion of variance in individuation (i.e., emotional and functional independence from parents). Individuation is a primary developmental task in emerging adulthood whereby a balance between closeness and distance is achieved that promotes the ability to be self-sufficient within the context of the parental relationship (e.g., Arnett, 2015; Lapsley \& Woodbury, 2015). Dysfunctional individuation can result in an enmeshed or detached parental relationship and has been linked to negative mental health outcomes in adulthood (e.g., Lapsley \& Woodbury, 2015). As such, our replicated results negatively linking parental support and individuation are cause for concern and lend credence to the idea that parents and SAs may be inclined to experience difficulty with renegotiating the presence, level, and quality of support within the intercollegiate context. Similarly, across studies, parental athletic engagement was the sole involvement strategy that predicted depression, and this association was negative. Because SAs are more 
likely to experience mental health problems than general college students (e.g., Wolanin et al., 2015), these replicated results help identify a specific factor, that of parents' involvement in sport-related decisions and issues, which may help protect SAs from experiencing depression. Differential links between involvement and SAs' experiences were also present in both studies, such as how academic and athletic engagement promoted academic self-efficacy but detracted from emotional independence.

These results justify a place for parental education in college athletics. Helping parents garner an informed perspective on their involvement and its effects may be a viable, low-cost means by which SAs' risks for academic stress, athletic burnout, and decreased well-being can be mitigated. Key results that can be clearly identified as best practices within an education program for parents of SAs include the following: (a) matching the provision of support to the maturity of the SA so as not to overwhelm and potentially undermine the SA's independence on the field and in the classroom; (b) engaging the SA in conversations about their sport career to help the SA cope with possible depressive symptoms that may be tied to sport experiences; and (c) remaining in-the-know about sport and school experiences to best support the SA's positive feelings about and confidence in their academic skills.

\section{Limitations}

Despite the contributions made by the present research, it is not without limitations. First, our data are cross-sectional and only represents the SA perspective. As such, we cannot infer directionality of involvement-outcome associations (i.e., parent influence on child), speculate about the developmental trajectory of involvement-outcome links across the college years (i.e., freshman through senior), and determine if the same results would be found using parents' reports of their own involvement (i.e., reporter bias). To address these limitations, future researchers should employ longitudinal designs and collect multi-method data from multiple reporters. To the latter point, integrating parents as participants is a necessary step for designing programmatic interventions. After all, if the key targets for intervention (i.e., parents) do not find the program to be useful, relatable, or accessible, they will not partake and the purported benefits of participation (i.e., positive involvement and enhanced SA experiences) will not occur.

Second, all our outcome measures related to the SA experience were subjective. Future work should include objective outcome measures such as time to graduation, likelihood of receiving mental health counseling, and biological markers of stress. Exploring links between parenting and SA stress biomarkers is an important and untapped vein of work considering, for instance, SAs experience sleep problems that can negatively affect athletic performance (e.g., Mah, Mah, Kezirian, \& Dement, 2011). Last, only one institution per division was represented in our sample. Thus, replication of the present study with a larger sample of schools and SAs within each division is needed to validate our results. To address this limitation, the NCAA and its member institutions must endorse and financially support future research dedicated to this effort to ensure the realization of a generalizable education program for parents of SAs. 


\section{Conclusion}

Results from the present study provide novel evidence for an absence of divisionwide differences in mean levels of parental involvement and an absence of variability in associations between involvement and SAs' experiences by division. Our findings thus suggest that regardless of NCAA division and beyond key demographic variables, SAs similarly experience moderately high levels of involvement that promote academic, athletic, and well-being outcomes, but detract from gaining independence. This may assist in the creation of educational programming for parents of SAs that has been requested by key athletic stakeholders, as the only way an evidence-based, national intercollegiate sport parent program can begin to take shape is by first determining if parents' involvement is equivalent across NCAA divisions. Our findings also address the gap in research on parental involvement between youth sport and intercollegiate sport, provide support for the multidimensional construct of parental involvement and its links to college student development (e.g., Lowe \& Dotterer, 2017), highlight the parental role during emerging adulthood and the mastery stage of a SA's career (e.g., Arnett, 2015; Côté, 1999), and affirm the importance of involvement strategies that balance support provision with respecting emerging adults' developing autonomy in the context of intercollegiate sport.

\section{References}

Aiken, L.S., \& West, S.G. (1991). Multiple regression: Testing and interpreting interactions. Thousand Oaks, CA: Sage.

Aquilino, W.S. (2006). Family relationships and support systems in emerging adulthood. In J.J. Arnett, \& J.L. Tanner (Eds.), Emerging adults in America: Coming of age in the 21st century (pp. 193-217). Washington, DC: American Psychological Association.

Arnett, J.J. (2000). Emerging adulthood: A theory of development from the late teens through the twenties. American Psychologist, 55, 469-480. PubMed ID: 10842426 doi:10.1037/0003-066X.55.5.469

Arnett, J.J. (2015). Emerging adulthood: The winding road from the late teens through the twenties (2nd ed.). New York, NY: Oxford University Press.

Bachman, J.G., Johnston, L.D., O’Malley, P., \& Schulenberg, J. (1996). Transition in drug use during late adolescence and young adulthood. In J.A. Graber, J. Brooks-Gunn, \& A.C. Peterson (Eds.), Transitions through adolescence: Interpersonal domains and context (pp. 111-140). Mahwah, NJ: Erlbaum.

Bastie, F. (2017, October 4). Recruiting column: How college coaches evaluate parents. USA Today High School Sports. Retrieved from http://usatodayhss.com/2017/ recruiting-column-how-college-coaches-evaluate-parents

Chen, Y.F., \& Katz, J.E. (2009). Extending family to school life: College students' use of the mobile phone. International Journal of Human-Computer Studies, 67, 179-191. doi: 10.1016/j.ijhcs.2008.09.002

Cosh, S., \& Tully, P.J. (2015). Stressors, coping, and support mechanisms for student athletes combining elite sport and tertiary education: Implications for practice. The Sport Psychologist, 29, 120-133. doi:10.1123/tsp.2014-0102

Côté, J. (1999). The influence of the family in the development of talent in sport. The Sport Psychologist, 13, 395-417. doi:10.1123/tsp.13.4.395 
Côté, J., Baker, J., \& Abernethy, B. (2007). Practice and play in the development of sport expertise. In R. Eklund, \& G. Tenenbaum (Eds.), Handbook of sport psychology (3rd ed., pp. 184-202). Hoboken, NJ: Wiley.

Cronbach, L.J. (1951). Coefficient alpha and the internal structure of tests. Psychometrika, 16(3), 297-334. doi:10.1007/BF02310555

Dorsch, T.E., King, M.Q., Dunn, C.R., Osai, K.V., \& Tulane, S. (2017). The impact of evidence-based parent education in organized youth sport: a pilot study. Journal of Applied Sport Psychology, 29, 199-214. doi:10.1080/10413200.2016.1194909

Dorsch, T.E., Lowe, K., Dotterer, A.M., \& Lyons, L. (2016a). Parent involvement in young adults' intercollegiate athletic careers: Developmental considerations and applied recommendations. Journal of Intercollegiate Sport, 9, 1-26. doi:10.1123/jis.2015-0013

Dorsch, T.E., Lowe, K., Dotterer, A.M., Lyons, L., \& Barker, A. (2016b). Stakeholders' perceptions of parent involvement in young adults' intercollegiate athletic careers: Policy, education, and desired outcomes. Journal of Issues in Intercollegiate Athletics, 9, 124-141. Retrieved from http://csri-jiia.org

Dunn, R.C., Dorsch, T.E., King, M.Q., \& Rothlisberger, K.J. (2016). The impact of family financial investment on perceived parent pressure and child enjoyment and commitment in organized youth sport. Family Relations, 65, 287-299. doi:10.1111/ fare. 12193

Fingerman, K., Miller, L., Birditt, K., \& Zarit, S. (2009). Giving to the good and the needy: Parental support of grown children. Journal of Marriage and Family, 71, 1220-1233. PubMed ID: 20161599 doi:10.1111/j.1741-3737.2009.00665.x

Fingerman, K.L., \& Yahirun, J.J. (2015). Emerging adulthood in the context of family. In J. J. Arnett (Ed.), The oxford handbook of emerging adulthood (pp. 163-189). New York, NY: Oxford University Press.

Fredricks, J.A., \& Eccles, J.S. (2005). Family socialization, gender, and sport motivation and involvement. Journal of Sport and Exercise Psychology, 27, 3-31. doi:10.1123/ jsep.27.1.3

Gregory, S. (2017, August 24). How kids' sports became a \$15 billion industry. Time Magazine. Retrieved from http://time.com/magazine/us/4913681/september-4th2017-vol-190-no-9-u-s/

Harper, C.E., Sax, L.J., \& Wolf, D.S.S. (2012). The role of parents in college students' sociopolitical awareness, academic, and social development. Journal of Student Affairs Research and Practice, 49, 137-156. doi:10.1515/jsarp-2012-6147

Hoffman, J.A. (1984). Psychological separation of late adolescents from their parents. Journal of Counseling Psychology, 31, 170-178. doi:10.1037/0022-0167.31.2.170

Jafar, A. (2012, January 23). Consumerism in higher education: The rise of the helicopter parent. Guardian News and Limited Media. Retrieved from http://www.theguardian. $\mathrm{com} / \mathrm{us}$

Kenyon, D.B., \& Koerner, S.S. (2009). Examining emerging-adults' and parents' expectations about autonomy during the transition to college. Journal of Adolescent Research, 24, 293-320. doi:10.1177/0743558409333021

Kins, E., Soenens, B., \& Beyers, W. (2012). Parental psychological control and dysfunctional separation-individuation: A tale of two different dynamics. Journal of Adolescence, 35, 1099-1109. PubMed ID: 22445217 doi:10.1016/j.adolescence. 2012.02.017

Kohout, F.J., Berkman, L.F., Evans, D.A., \& Cornoni-Huntley, J. (1993). Two shorter forms of the CES-D depression symptoms index. Journal of Aging and Health, 5, 179-193. PubMed ID: 10125443 doi:10.1177/089826439300500202

Lapsley, D., \& Woodbury, R.D. (2015). Social cognitive development in emerging adulthood. In J.J. Arnett (Ed.), The Oxford handbook of emerging adulthood (pp. 142-159). New York, NY: Oxford University Press. 
Lefkowitz, E.S., Vukman, S.N., \& Loken, E. (2012). Young adults in a wireless world. In A. Booth \& S.M. McHale (Eds.), Early adulthood in a family context (pp. 45-56). New York, NY: Springer.

Lochbaum, M.R., \& Roberts, G.C. (1993). Goal orientations and perceptions of the sport experience. Journal of Sport \& Exercise Psychology, 15, 160-171. doi:10.1123/jsep. 15.2.160

Lowe, K., \& Dotterer, A.M. (2017). Parental involvement during the college transition: A review and suggestion for its conceptual definition. Journal of Adolescent Research Review, 3, 29-42. doi:10.1007/s40894-017-0058-z

Mah, C.D., Mah, K.E., Kezirian, E.J., \& Dement, W.C. (2011). The effects of sleep extension on the athletic performance of collegiate basketball players. Sleep, 34(7), 943-950. PubMed ID: 21731144 doi:10.5665/SLEEP.1132

Malina, R.M. (2010). Early sport specialization: Roots, effectiveness, risks. Current Sports Medicine Reports, 9, 364-371. PubMed ID: 21068571 doi:10.1249/JSR. 0b013e3181fe3166

Midgley, C., Maehr, M.L., Hruda, L.Z., Anderman, E., Anderman, L., Freeman, K.E., . . . Urdan, T. (2000). Manual for the patterns of adaptive learning scales. Ann Arbor, MI: University of Michigan.

National Collegiate Athletic Association (NCAA). (2016). Results from the 2015 GOALS study of the student-athlete experience. Retrieved from http://www.ncaa.org/sites/ default/files/GOALS_convention_slidebank_jan2016_public.pdf

National Collegiate Athletic Association (NCAA). (2017a). Estimated probability of competing in college and professional athletics. Retrieved from http://www.ncaa. org/sites/default/files/2015-16RES_Probability_Chart_Web_20170314.pdf

National Collegiate Athletic Association (NCAA). (2017b). NCAA study of studentathlete social environments (2012-2016): January 2017 preliminary report. Retrieved from http://www.ncaa.org/sites/default/files/2017RES_NCAA_Convention_Social_ Environments_present_20170807.pdf

National Collegiate Athletic Association (NCAA). (2018). NCAA 101: Our three divisions. Retrieved from http://www.ncaa.org/sites/default/files/18-00037\%20NCAA\% 20101\%20-\%20Our\%20Three\%20Divisions\%20Updates\%20_WEB.pdf

National Youth Sports Health \& Safety Institute. (2013). Youth sports parent pledge. Retrieved from http://nyshsi.org/wp-content/uploads/2014/10/NYSHSI-Parent Pledge. pdf?pdf=parent-pledge

Nelson, L.J., \& Barry, C.M. (2005). Distinguishing features of emerging adulthood: The role of self-classification as an adult. Journal of Adolescent Research, 20, 242-262. doi: $10.1177 / 0743558404273074$

Niemiec, C.P., Lynch, M.F., Vansteenkiste, M., Bernstein, J., Deci, E.L., \& Ryan, R.M. (2006). The antecedents and consequences of autonomous self-regulation for college: A self-determination theory perspective on socialization. Journal of Adolescence, 29, 761-775. doi:10.1016/j.adolescence.2005.11.009

O'Rourke, D.J., Smith, R.E., Smoll, F.L., \& Cumming, S.P. (2014). Relations of parent- and coach-initiated motivational climates to young athletes' self-esteem, performance anxiety, and autonomous motivation: Who is more influential? Journal of Applied Sport Psychology, 26, 395-408. doi:10.1080/10413200.2014.907838

Parietti, M.L., Sutherland, S., \& Pastore, D.L. (2017). Parental involvement in the lives of intercollegiate athletes. Journal of Amateur Sport, 3, 106-134. doi:10.17161/jas.v3i3. 6510

Powell, D.R. (2005). Searches for what works in parenting interventions. In T. Luster \& L. Okagaki (Eds.), Parenting: An ecological perspective (2nd ed., pp. 343-376). New York, NY: Routledge. 
Reeve, J. (2013). How students create motivationally supportive learning environments for themselves: The concept of agentic engagement. Journal of Educational Psychology, 105, 579-595. doi:10.1037/a0032690

Settersten, R.A. (2012). The contemporary context of young adulthood in the USA: From demography to development, from private troubles to public issues. In A. Booth \& S.M. McHale (Eds.), Early adulthood in a family context (pp. 3-26). New York, NY: Springer.

Stein, G.L., Raedeke, T.D., \& Glenn, S.D. (1999). Children's perceptions of parent involvement: It's not how much, but to what degree that's important. Journal of Sport Behavior, 22, 591-601. Retrieved from http://www.southalabama.edu/colleges/ artsandsci/psychology/Journal_of_Sport_Behavior.html

Tabachnick, B.G., \& Fidell, L.S. (2013). Using multivariate statistics (6th ed.). New York, NY: Allyn \& Bacon/Pearson Education.

Turrisi, R., Mastroleo, N.R., Mallett, K.A., Larimer, M.E., \& Kilmer, J.R. (2007). Examination of the mediational influences of peer norms, environmental influences, and parent communications on heavy drinking in athletes and nonathletes. Psychology of Addictive Behaviors, 21(4), 453-461. PubMed ID: 18072827 doi:10.1037/0893164X.21.4.453

Udry, J.R. (1998). The National Longitudinal Study of Adolescent Health (Add Health), Waves I \& II, 1994-1996 (Data Sets 48-50, 98, A1-A3, Kelley, M.S. \& Peterson J.L.) [machine- readable data file and documentation]. Chapel Hill, NC: Carolina Population Center, University of North Carolina at Chapel Hill (Producer). Los Altos, CA: Sociometrics Corporation, American Family Data Archive (Producer \& Distributor).

Wechsler, H., Davenport, A.E., Dowdall, G.W., Grossman, S.J., \& Zanakos, S.I. (1997). Binge drinking, tobacco, and illicit drug use and involvement in college athletics: A survey of students at 140 American colleges. Journal of American College Health, 45, 195-200. PubMed ID: 9069676 doi:10.1080/07448481.1997.9936884

Wei, M., Russell, D.W., \& Zakalik, R.A. (2005). Adult attachment, social self-efficacy, self- disclosure, loneliness, and subsequent depression for freshman college students: A longitudinal study. Journal of Counseling Psychology, 52, 602-614. doi:10.1037/ 0022-0167.52.4.602

Wolanin, A., Gross, M., \& Hong, E. (2015). Depression in athletes: Prevalence and risk factors. Current Sports Medicine Reports, 14(1), 56-60. PubMed ID: 25574886 doi:10.1249/JSR.0000000000000123

Wolf, D.S., Sax, L.J., \& Harper, C.E. (2009). Parental engagement and contact in the academic lives of college students. NASPA Journal, 46, 325-358. doi:10.2202/19496605.6044

Wylleman, P., De Knop, P.D., Verdet, M.C., \& Cecič-Erpič, S. (2007). Parenting and career transitions of elite athletes. In S. Jowett \& D. Lavallee (Eds.), Social psychology in sport (pp. 233-247). Champaign, IL: Human Kinetics Publishers.

Wylleman, P., \& Lavallee, D. (2004). A developmental perspective on transitions faced by athletes. In M. Weiss (Ed.), Developmental sport and exercise psychology: A lifespan perspective (pp. 507-527). Morgantown, WV: Fitness Information Technology. 